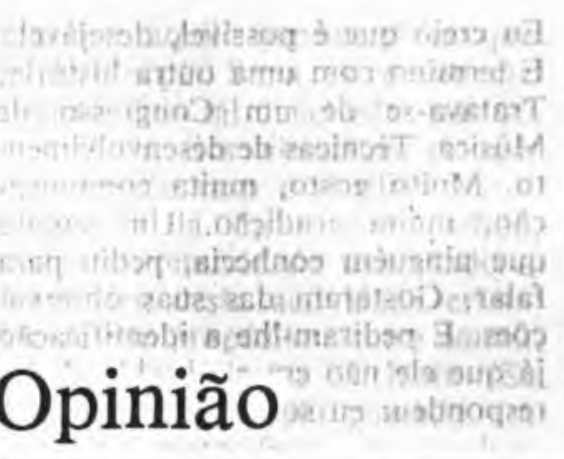

का

O que é que o Principezinho pensaria se visitasse hoje a nossa Universidade?

$\mathrm{Na}$ sua conversa com o aviador - Principezinho declara que não gosta de "senhores sisudos". Ao que me parece os senhores sisudos pagam-lhe da mesma moeda. Nesta sociedade em que vivemos, muito séria e compenetrada discutindo direitos e deveres (sobretudo direitos), deslocando-se de Comissão em Comissão, perdeu-se, quase, a noção de humor. $\mathrm{O}$ espírito infantil, a alegria, o actuar como acção lúdica, de jogo, de prazer. Tive recentemente contacto com um investigador que me disse que a razão principal pela qual investigava era "pour s'amuser". E que tinha dito isso numa reunião. Pois bem, foi "chamado à ordem" posteriormente. Disseram-lhe (os tais senhores sisudos) "que a investigação era uma coisa que se devia levar a sério que não era para rir".

Li há algum tempo o relato, alarmante, quanto a mim, de um jovem empregado num centro de cálculo dos Estados Unidos que preocupado com a dieta e calorias fez um programa para o computador de bolso que lhe ia contabilizando as calorias que ia ingerindo ao longo do dia. Â noite "perguntou" ao computador se podia comer um chocolate que the apetecia. O computador, sadicamente, disse-lhe que não e ele... não comeu. Penso que há prioridades e prioridades, que se pode querer fazer uma dieta rigorosa, que há ocasiôes em que isso se justifica. Não sei as condiçðes concretas em que este caso se aplica. Talvez fosse e seja justificável em certas alturas. Mas cuidado, não haverá o perigo de uma inversão de valores? Um domínio da máquina sobre o homem?

É este no fundo o alerta que eu pretendo trazer aqui. A mensagem que eu quero trazer resulta muito

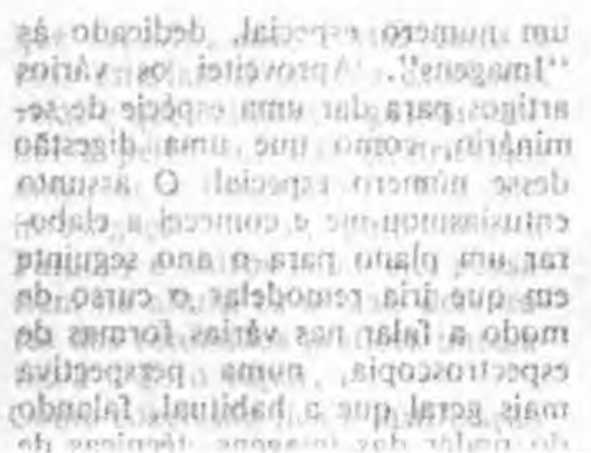

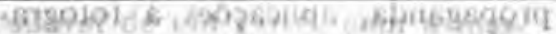

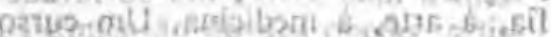

da experiência de quem começou a dar aulas em 1960 , já lá vai um bom par de anos. Não trago aqui um atestado de velhice. Muito pelo contrário. Procuro situar-me na perspectiva de um texto desse pensador sagaz que foi $o$ brasileiro Gustavo Corção (engenheiro, aliás), que no livro Fronteiras da Técnica fala deslumbrado de uma missa a que assistiu onde um padre velhinho afirmou: Deus é a alegria da minha juventude. Não comento a frase.

É neste sentido que Illich propõe a inversão das instituiçōes. É neste sentido que ele introduz o tema convivialidade. É neste sentido que Marcuse fala no sentido lúdico da actividade humana. $\mathrm{O}$ gozo do aprender, o gosto de saber, o interesse pelo progresso do conhecimento.

Apresentei em tempo, num Encontro Universitário, um texto subordinado ao título: A Universidade, feira franca de cultura. Gostaria aqui de ir um pouco mais longe. Proponho que docentes e gestores readquiram o espirito inicial da Universidade, centro de saber, não único na sociedade, evidentemente, pois nåo podemos esquecer os museus, os monumentos, as livrarias, o teatro e cinema, as tertúlias e até as reuniðes de café, outros tantos centros de cultura, para só citar alguns. Mas a Universidade é um centro privilegiado. Ponto de encontro de uma oferta e de uma procura da cultura.

Retorno às origens. Aos tempos em que era com alegria que se juntava um grupo para ouvir alguém que tinha qualquer coisa a dar do ponto de vista de conhecimentos.

A Universidade deve ser pará formar mentalidades. E por definição um centro onde se comunicam estudos superiores. Mas o que é que se deve entender por superiores? Superiores em quê? Alguém pode negar a importância de um estudo na pré-primária, ou mesmo in-

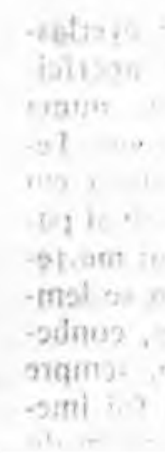

(p)

fantil? Onde é que é na Universidade o superior? Por ser terminal? Então isso significa que os que não são universitários são inferiores? Se repararem bem eu toco aqui um ponto importante. O nosso hábito social criou infelizmente, o mito do canudo. Em certos meios criou-se a noção de que quem não tem um curso superior é um inferior. Mas a aquisição do tal estatuto de ser superior é feito com um sentido a que eu chamaria de trabalho forçado. É a luta pelo poder, e não a luta pelo saber. Quer ter-se o canudo não como sinal de maturidade mas como sinal de superioridade.

Mas no fundo superioridade em quê e para quê? Como aqueles homenzinhos muito ocupados, que me fazem pena porque não são capazes de apreciar a beleza de uma flor dos campos. E cai-se em cheio na descrição do Principezinho dos senhores sisudos. Ocupados, preocupados, sem alegria. Enfronhados nos seus negócios, anéis nos dedos gordurosos, untuosos, charuto na boca, incapazes de rir.

Façamos da Aula uma festa. Façamos de um programa de Aulas um festival. Saber mais, compreender melhor o mundo que nos rodeia, ser capaz de sentir mais conscientemente o pulsar da evolução, o devir, o evoluir, ser capaz, por um esforço de vontade consciente, dominar a evolução. Tudo isso pode $\mathrm{e}$ deve constituir motivo de alegria. Não estou a escamotear os problemas, que são muitos. Nem mesmo 0 esforço de aprendizagem. $\mathrm{O}$ computador é preciso, e cada vez mais, nos nossos dias, como agente de compilação de memorização. O esforço criador e inovador é rigorosamente um esforço. "Dá trabalho" ensinar e aprender. Há um tempo para o chamado trabalho profissional, sério, no sentido de importante. Mas que deve ser assumido voluntariamente, com gozo, e portanto alegria.

Lembro-me de um texto de Ches- 
terton, no seu livro «The everlasting man». Tratava-se de aperfeiçoar a escrita hieroglifica, numa sala de um palácio, talvez em Tebas, eu sei lá. E o que estava em causa era a escolha de um sinal para a palavra sisudo, se bem me recordo do exemplo. Alguém se lembrou de um dos sacerdotes, conhecido de todos, carrancudo, sempre metido consigo. E a ideia foi imediatamente aprovada: a imagem do tal sacerdote ficou como símbolo. mas a escolha foi pontuada peto gargalhar que ressoou largamente pelas salas e corredores do palácio. Todos tiveram a noção de que se estavam a divertir. Bastava imaginar a cara do tal sacerdote quando lhe dissessem que a figura dele tinha sido escolhida para simbolo de sisudez.

Isso hoje seria feito, com certeza, no âmbito de uma Comissão, muito bem escolhida para o efeito, muito sisuda, compenetrada, que declaramos como nos livros, que qualquer semelhança com qualquer personalidade real seria pura coincidência. E a luta pelo poder continua. Nos numerus clausus, necessários talvez, o problema é discutivel, mas também sisudos e finos. Alguém se lembrou de entrevistar um candidato e perguntar-lhe se ele se lembrava de alguma anedota e entrar em linha de conta com isso na aprovação final?

Cores claras para as paredes. Visão clara, faces vivas, olhos despertos. Aulas dadas com entusiasmo tanto quanto possivel, por pessoas interessadas em comunicar perante pessoas realmente interessadas em aprender.

Poderão dizer os que me lêem que isto não passa de utopia, incompativel com o ritmo de sociedade em que vivemos. Mas não podemos nós, não devemos nós pôr em causa, e permanentemente, a sociedade em que vivemos? Será tla a melhor? Em que medida a podemos melhorar? O que é que será preferivel, ter mais dinheiro ou usar melhor o que temos?

Não. Não é utopia. Há experiências. Quem escreve estas linhas já sentiu isso, já experimentou isso. E no meio de umas quantas citaçōes que já fiz deixem-me agora apresentar um testemunho pessoal. Como prova de coerência, talvez o possa dizer.

Numa altura em que estara encarregado da regência da Cadeira de Espectroscopia foi publicado um número da revista $\mathrm{La}$ Recherche, um número especial, dedicado às "Imagens". Aproveitei os vários artigos para dar uma espécie de seminário, como que uma digestão desse número especial. $\mathrm{O}$ assunto entusiasmou-me e comecei a claborar um plano para o ano seguinte em que iria remodelar o curso de modo a falar nas várias formas de espectroscopia, numa perspectiva mais geral que a habitual, falando do poder das imagens, técnicas de propaganda, aplicaçð̋es à fotografia, à arte, à medicina. Um curso de espectroscopia alargado, que me parecia inovador, e do qual tirando eu prazer procuraria interessar também os Alunos, dando-lhes também prazer em ouvir.

Logo por azar (ou seriam as forças negativas da Evolução a trabalhar?) fui confrontado com uma situação complicada no Departamento. Seria de certo modo "autorizado" a dar algumas horas de curso, mas integradas num plano geral, nos moldes tradicionais, sendo obrigado a atender ao que era dado antes e ao que seria dado depois. No fim de semana a seguir fiz uma reunião magna comigo próprio. E por unanimidade e aclamação eu e eu aprovámos não aceitar. O confronto entre os dois "modelos" pedagógicos era demasiado grande. E desliguei-me da cadeira.

Talvez seja criticável, para alguns, esta atitude. Para mim representou um certo sacrificio mas ao mesmo tempo uma prova de coerência, Continuar nos moldes propostos, e impostos, era engrossar o rol dos senhores sisudos.

A melhoria dos laboratórios, a melhoria do processo de coordenação, o uso de novas técnicas, o estudo dos novos dados, nada disso é incompatível com o gozo de ensinar. A palavra Universidade é da familia do Universo, de globalidade. Ora o todo em que vivemos é um todo alegre, não enfadonho.

E podemos voltar ao Principezinho. A raposa quer saber a que horas é que o Principezinho a vai visitar, para poder antes gozar a visita. Alguém acredita que da parte de um Aluno, hoje em dia, e na generalidade dos casos, ele pense com alegria que, por exemplo no dia seguinte, às 10 horas vai ter a alegria de um Encontro sobre o saber, na Aula tal e tal?

Fala-se muito hoje em dia em técnicas novas. Novas metodologias. Não será isto, ao seu retorno e. ideias antigas, uma renovação? Não poderá ser esta uma meta a atingir?
Eu creio que é possivel, desejável. E termino com uma outra história. Tratava-se de um Congresso de Música. Técnicas de desenvolvimento. Muito gosto, muita comunicação, muita erudição. Um sujeito que ninguém conhecia, pediu para falar. Gostaram das suas observaçðes. E pediram-Ihe a identificação já que ele não era conhecido. E ele respondeu: eu sou músico..

\section{J. C. Conte}

Centro de Quimica-Fisica Molecular, Complexo I, Instituto Superior Técnico - Lisboa.

\section{Para que serve a Investigação Científica?}

Quem se dedica à investigação científica, ouviu com toda a certesa a pergunta - Para que serve? $\mathrm{Na}$ maioria dos casos o visado encontra qualquer coisa de prático, uma finalidade para a sua pesqui$z a$, que lhe permita justificar perante o seu interlocutor, o estatuto privilegiado de cientista. Estamos longe de 1920 quando o matemático italiano Gaetano Scorza respondia a pergunta idêntica - "Para nada. Se é uma coisa que nos agrada, não nos preocupamos para que serve. Mas é bela e tanto basta".

Por que razão o comportamento dos trabalhadores científicos se modificou entretanto, como naqueles cuja actividade se situa no domínio da investigação pura? A comunidade cientifica cresceu, a competição requer na maioria dos casos investimentos cada vez maiores, a competição entre grupos e mesmo a nivel individual é cada vez mais acentuada. A opinião pública quer resultados práticos, os governos justificar as verbas dispendidas. É preciso que a utilidade das pesquisas seja evidente.

Esta atitude retira ao trabalho científico a sua face de actividade cultural, fonte de dúvidas, mais do que de certezas.

Portanto à pergunta inicial «para que serve?», um leitor menos prevenido seria levado a concluir estarmos a sugerir que os trabalhadores cientificos sempre se têm divertido, ontem de uma forma assumida, hoje procurando uma justificação prática, sem se preocupa-

" Inspirado no artigo de Giorgio Tecce certezze" Scienza 5 (1968), 11. 
rem com aquilo que sucede ao que pð̃em de pé. Seria extremamente injusto tirar tal conclusão: não só a maioria dos cientistas se tem preocupado com o destino que a sociedade dá aos seus trabalhos, como a comunidade tem vindo a beneficiar desta actividade criativa. A este propósito ocorre contar a seguinte reflexão de Nott "Sè nos finais do século passado um governo pretendesse desenvolver os sistemas de iluminação, dentro de uma perspectiva da investigação aplicada limitada à questão "para que serve?", nas nossas casas e ruas estariamos usando excelentes velas e queimadores a gás ou mesmo a petróleo... Da electricidade ninguém se lembraria!!' Era uma investigação inútil, para divertir Faraday e outros como ele, pensariam na altura os actuais defensores dos resultados práticos imediatos a todo o vapor.

Como conclusão fica a justificação do trabalho científico património cultural de um Povo, com a mesma dimensão do dos poetas, artistas, escritores, músicos. A obra vale por si própria. Cabe a todos nós usar da melhor maneira, aquilo que os artistas, pensadores, cientistas e outros criadores, acrescentam à cultura da humanidade. E depois há sempre um Edison pronto a inventar uma lâmpada de onde nasça a luz.

Fernando Pina

Faculdade de Ciências e Tecnologia Universidade Nova de Lisboa.

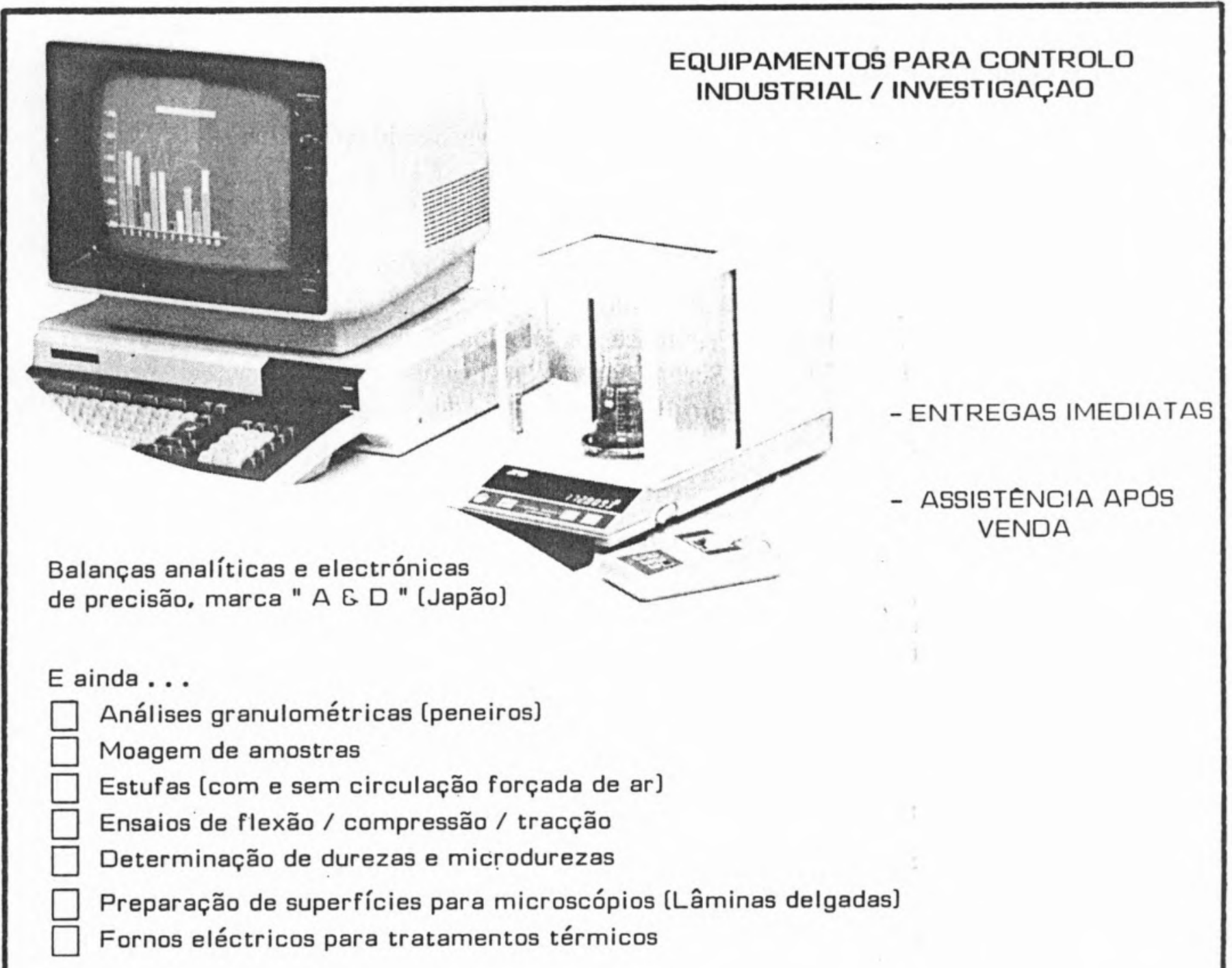

\section{VIARA COMERCIAL(MÁQUINAS),LDA}

SEDE: Rua Delfim Ferreira, $509-4100$ Porto telefones: $683763 / 671351 / 671352$ telex: 26602

FILIAL: Av. do Brasil: 145-C - 1700 Lisboa telefones: $804551 / 2$ 


\section{SOCIEDADE PORTUGUESA DE QUIMMICA}

Avenida da República, $37 \cdot 4 .^{\circ}-1000$ LISBOA

\section{REACÇÕES ÁCIDO-BASE}

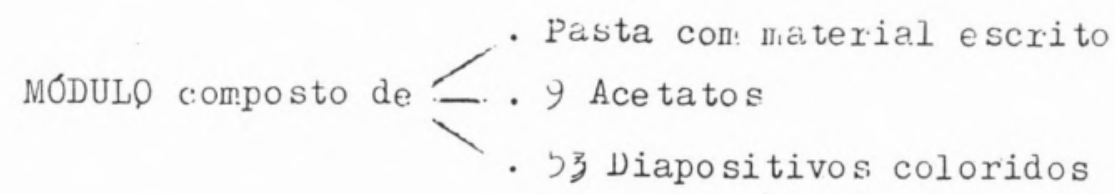

por Jean-Max Dumas, Doutor em Ciências

com a colaboração técnica de Joel Monteau, Doutor de $3 .^{\circ}$ ciclo

Centro Universitário dos Novos Media de Ensino, Universidade de Poitiers

Tradução e adaptação do meterial escrito e ạtatos

Artur Marques da Costa, Colégio Militar, Lisboa

Herta Beckert, Escola Secundária da Amadora

Maria Elisa Maia, Departamento de Química da Faculdade de Ciências de Lisboa

Maria da Vistação Barbosa, Escola Secundária de Queluz

Mariana P.B.A. Pereira, Departamento de Educação da Faculdade de Ciências de Lisboa

Este módulo destina-se essencialmente a:

Quimicotecnia - $10 .^{\circ}$ e $11 .^{\circ}$ anos

Química $\quad-11 .^{\circ}$ e $12 .^{\circ}$ anos

Química $\quad-1 .^{\circ}$ ano das Universidades

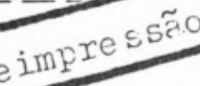

Nome

Morada

Escola....

Está disposto a colaborar na avaliação deste módulo?

Está interessado (ou a sua escola) na aquisição de: Pasta com II aterial e scri to

Colecção de 9 acetatos colecção de 58 diapositivos

(O preço das colecçōes de acetatos e diapositivos será enviado a quem o solicitar, numa carta que contenha um envelope sclado e endereçado)

Envio cheque n. $^{\circ}$ do Banco no valor de. $750 \$ 00$ (pasta com. material escrito) + $100 \$ 00$ (embalagem e ervio) 